\title{
Kultur. Gut. Erzählen
}

\section{Reiseliteraturen und kulturelles Erbe Europas}

\section{Eine Kabinettausstellung in der Württem- bergischen Landesbibliothek \\ 28. August bis 5. Oktober 2018}

2018 wird das Jahr des europäischen Kulturerbes mit einer Vielzahl von Veranstaltungen gefeiert, die einen regelrechten „Heritage Boom" ausgelöst haben.

Doch wie entsteht kulturelles Erbe? Was formt unser Bild von Europa? Die Ausstellung der Württembergischen Landesbibliothek widmete sich diesen Fragen und nahm Reiseerzählungen sowie Publikationen in den Blick, die sich mit dem Thema Kulturerbe und Europa als Erinnerungsort aus kulturwissenschaftlicher Perspektive befassen.

Es gibt unzählige Vorstellungen davon, was Europa ist. Was diese verbinden kann, ist geschichtliche, kulturelle und ästhetische Erfahrung. Reiseliteraturen sind schriftliche Zeugnisse, die von fremden Ländern und Kulturen berichten. Die literarischen Formen sind dabei vielfältig: Es gibt sie als Reiseromane, Reiseberichte, Reiseführer, Handbücher über fremde Länder und Kulturen, Reisetagebücher, Briefe und Gedichte über das Reisen und die Reiseerfahrung. Reisende sind in Bewegung, sie erfahren Neues, Unbekanntes, nie Dagewesenes oder Unerhörtes, manchmal aber auch nur Immergleiches im Zeitalter des Massentourismus. Im Erleben einer Reise, umso mehr einer neuen Kultur, werden das Eigene und das Fremde, Ferne und Nähe, Vorstellung und Realität abgeglichen. Europa ist in diesem Sinne auch ein reiseliterarisches Konstrukt, das von der Wahrnehmung und Inszenierung seiner Reisenden und Schreibenden abhängt. Die Darstellung Europas in Reiseliteraturen trägt dazu bei, eine Vorstellung von dem zu formen, was Kultur ist, was Kultur sein kann oder auch, was vermeintlich aus der Kultur ausgegrenzt bleiben soll. Reiseliteraturen tragen dazu bei, das kollektive Gedächtnis und das gemeinsame kulturelle Erbe von Menschen oder Volksgruppen, also auch die Vorstellung dessen, was Europa ist und sein kann, zu formen. Kultur kann auf diese Weise als etwas Überliefertes, Gewordenes und Gemachtes, aber auch als etwas Werdendes verstanden werden.
Die Ausstellung zeigte Publikationen aus dem Bereich der Heritage Studies (Kulturerbeforschung), Veröffentlichungen über Reiseerzählungen als kulturellem Erbe und über das kulturelle Erbe als Erzählung sowie Bücher, die von den „wilden“ Grenzen Europas und ihrer Kulturen handeln. Abschließend wurde der Fokus auf weibliche Reisende sowie auf humoristische Darstellungen Europas gelenkt.

Kuratorin: Dr. Ida Danciu

Ida Danciu

\section{Kultur. Gut. Erzåhlen}

Reiseliteraturen und kulturelles Erbe Europas

Eine Kabinettausstellung

28. August bis 5. Oktober 2018 Württembergische Landesbibliothek

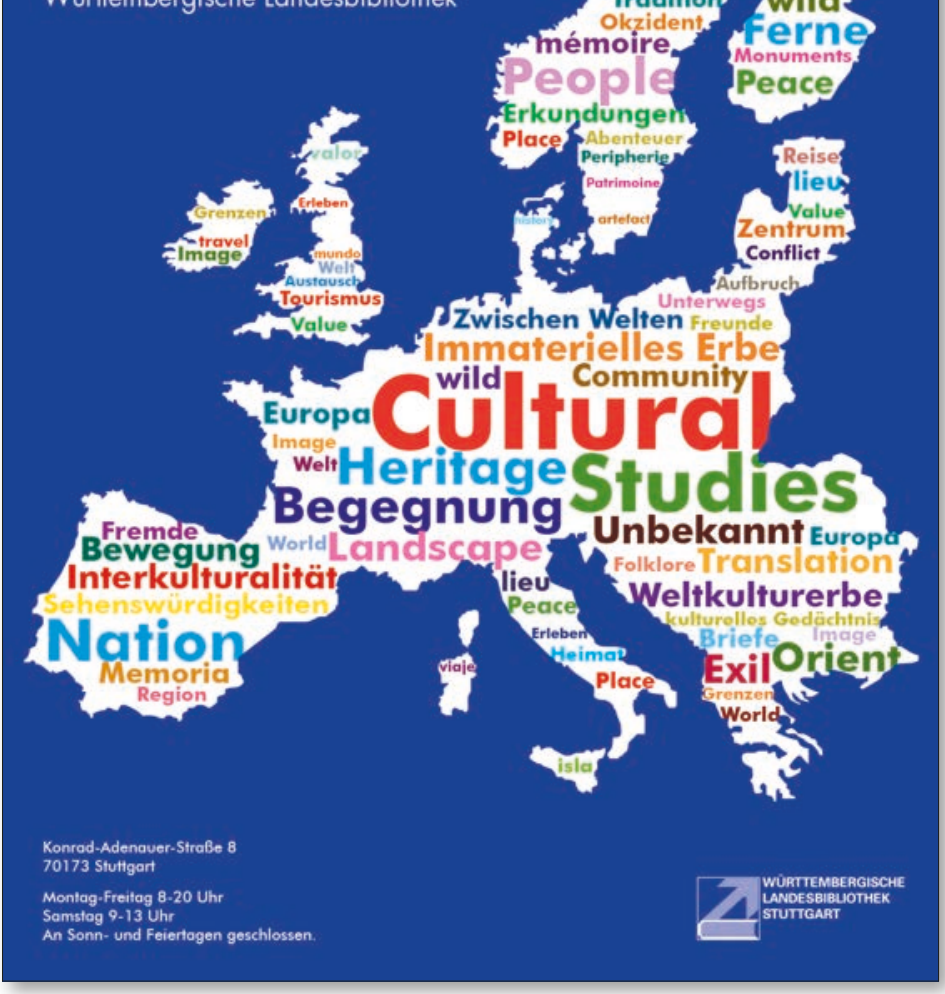

Illustration: Cultural Heritage/Gestaltung: Krieger Projektgestaltung 